\title{
A COMPARISON OF KANBAN-LIKE CONTROL STRATEGIES IN A MULTI-PRODUCT MANUFACTURING SYSTEM UNDER ERRATIC DEMAND
}

\author{
Chukwunonyelum E. Onyeocha \\ Enterprise Process Research Centre \\ Sch. of Mechanical \& Manufacturing Engineering \\ Dublin City University \\ Dublin 9, IRELAND
}

\author{
Joseph Khoury \\ Methode Electronics Malta Limited \\ Industrial Estate Mriehel \\ Qormi, BRK 3000, MALTA
}

\author{
John Geraghty \\ Enterprise Process Research Centre \\ Sch. of Mechanical \& Manufacturing Engineering \\ Dublin City University \\ Dublin 9, IRELAND
}

\begin{abstract}
Managing demand variability is a challenging task in manufacturing environments. Organizations that implemented Kanban-Like Production Control Strategies (PCS) especially in a multi-product manufacturing environment (MPME) plan a large volume of production authorization cards (PAC) to respond to demand variability. The issue associated with high PAC for each part-type in a MPME is proliferation of Work-In-Process (WIP). Shared Kanban Allocation Policy (S-KAP) was recently proposed in the literature to allow various part-types to share PAC. An advantages of this, is that when there is a corresponding shift in demand within part-types in a MPME, the system quickly responds by allocating PAC accordingly to part-types without recourse to re-planning/re-scheduling of PAC. This paper investigates the performance of a newly developed Basestock-Kanban-CONWIP (BK-CONWIP) Control Strategy in a four-product-five-stage manufacturing system with erratic demand. Simulation based optimization was used and it is shown that BK-CONWIP operating S-KAP will outperform other Kanban-Like PCS.
\end{abstract}

\section{INTRODUCTION}

Manufacturing organizations are continuously challenged by the evolving global market to offer a variety of products to customers' demands at relatively lower price and shorter lead times. Many of these manufacturing industries have adopted pull Production Control Strategies (PCS) in order to respond effectively to this challenge. Kanban-Like PCS are a class of pull PCS that utilize a card attached to a part to limit inventory and wholly or partially authorize production within a production stage (e.g., Kanban card), production segment or an entire line (e.g., CONWIP card). The card provides a visual aid to operators to determine whether production of a part is required and to supervisors to determine the status of a product in its production path. The adoption of a Kanban-Like PCS is often considered by manufacturing organizations because it tends to show lesser flow line congestions, are simpler to control than push strategies and have the ability to control WIP of a stage or system while monitoring the throughput of the system. 
Onyeocha, Khoury, and Geraghty

Table 1: Acronyms used in this paper.

\begin{tabular}{ll|ll}
\hline Acronym & Description & Acronym & Description \\
\hline PCS & Production Control Strategy & KAP & Kanban Allocation Policy \\
BK-CONWIP & Basestock Kanban CONWIP control strategy & D-KAP & Dedicated Kanban Allocation Policy \\
BSCS & Basestock Control Strategy & S-KAP & Shared Kanban Allocation Policy \\
CONWIP & Constant Work In Process control strategy & KAP+PCS & A specified KAP and specified PCS combination \\
EKCS & Extended Kanban Control Strategy & Other & Other abbreviations used in paper \\
GKCS & Generalised Kanban Control Strategy & MPME & Multi-Product Manufacturing Environment \\
HK-CONWIP & Hybrid Kanban CONWIP control strategy & PAC & Production Authorisation Card \\
KCS & Kanban Control Strategy & WIP & Work In Process inventory \\
\hline
\end{tabular}

Organizations that adopt Kanban-Like PCS are primarily challenged with the selection and implementation of an appropriate strategy for their systems that would adequately and rapidly respond to customers' demands in the shortest possible time and at a reduced cost. This challenge is more pronounced and complex in multi-product manufacturing environments with erratic demand patterns. The majority of the research on Kanban-Like PCS has focused on single product manufacturing environments (Satyam and Krishnamurthy 2008; Krajewski et al. 1989; Deleersnyder et al. 1992; Lee 1989; Spearman et al. 1990; Onyeocha and Geraghty 2012). Studies that considered multi-product manufacturing environments concentrated on areas such as: planning and scheduling (Akurk and Erhun 1999, Hum and Lee 1998), and optimization of production control parameters (Bard and Golany 1991). Other studies in multi-product manufacturing environments investigate the behavior of a particular strategy, for instance, the evaluation of the effect of the WIP limit of CONWIP (Satyam and Krishnamurthy 2008; Duenyas 1994; Ryan et al. 2000; Ryan and Vorasayan 2005). These studies assumed that production authorization cards are rigid and dedicated to a part-type in a system. However, the study of Baynat et al. (2002), considered production authorization cards to either be rigid (dedicated solely to a part-type) or be flexible (sharable among part-types). The two production authorization card policies are known as Dedicated Kanban Allocation Policy (D-KAP) and Shared Kanban Allocation Policy (S-KAP).

This paper investigates and compares the performance of several Kanban-Like PCS in a four-product five-stage manufacturing system with erratic demand using real industrial data with consideration of the Kanban Allocation Policy. Simulation based optimization was used to determine the control parameter settings for each scenario (KAP+PCS) examined. The responses of each scenario were investigated under changing demand profiles while the system configurations and control parameters settings remained unchanged. The results of this study are provided and discussed in this paper.

\section{MULTI-PRODUCT KANBAN-LIKE CONTROL STRATEGIES}

A Kanban Control Strategy (KCS) uses signal cards to release or authorize parts into a manufacturing system in response to actual demand. It controls WIP in a system, giving the system a certain level of production flexibility and decreases the production waste in a system, especially scrap and rework. Another benefit of KCS is that it minimizes the cycle time variability such that when the arrival rate is constant, cycle time is given by WIP divided by the arrival rate (Little's Law). Therefore, an increase in the WIP levels of the system will increase the cycle time of the products. A longer cycle time will result in a longer lead time, line congestion and low throughput in the system. Consequently, it is important to reduce the product's cycle time in order to achieve Just-In-Time delivery. The interest to reduce the product's cycle times large, non-repetitive and multi-product manufacturing environments led to the development of variations of KCS that are classified as Kanban-Like PCS.

Baynat et al. (2002), showed that there are two feasible policies for distribution of authorization cards with possibility of WIP reduction in a multi-product manufacturing environment. These policies were referred to as dedicated and shared Kanban allocation policies (D-KAP and S-KAP). S-KAP was shown to have the ability of using a lower number of planned production authorization cards to achieve lower or same WIP levels at a targeted service level when compared with D-KAP. it has been shown that some Kanban-Like PCS such as KCS, CONWIP, BSCS and HK-CONWIP are unable to operate S-KAP natu- 
rally (Baynat et al. 2002; Onyeocha and Geraghty 2012). Onyeocha and Geraghty (2012), proposed a modification approach to improve the control mechanisms of these Kanban-like PCS to enable them operate S-KAP. The application of their modification to HK-CONWIP resulted to a new strategy called BKCONWIP that is capable of operating S-KAP.

\subsection{Dedicated and Shared Kanban Allocation Policies}

In D-KAP, a planned number of production authorization cards are assigned to a specific part-type in a stage or system, for instance, if a distinctive quantity of production authorization cards is allocated to a specific part-type in a stage of a multi-product system, such that the part-type could only be authorized or released into a stage or system by a matching (same type assigned for such part-type) production authorization card (Baynat et al. 2002). Having several production authorization cards for each part-type in DKAP of Kanban-Like PCS causes proliferation of WIP in a multi-product system, leading to long lead time, low throughput and line congestion. Multi-product systems operating D-KAP function as a series of single product systems with shared manufacturing process units (Baynat et al. 2002; Onyeocha and Geraghty 2012). Onyeocha and Geraghty (2012), showed that the tight-coupling between demand information and authorization cards is causing principle reason for D-KAP systems operating extended single product systems.

In S-KAP, a specified quantity of production authorization cards is assigned for authorization of all part-types in a stage or the entire system such that if there is an available production authorization card, it will respond to any available demand irrespective of the part-type. The production authorization cards are planned and scheduled for a stage or system such that they can be distributed among part-types depending on demand information (Baynat et al. 2002; Onyeocha and Geraghty 2012). Onyeocha and Geraghty (2012) proposed that if there is a corresponding shift in product volume within part-types in a multiproduct system, S-KAP quickly responds to such volume change by distributing production authorization cards accordingly to part-types without recourse to re-planning or re-scheduling of authorization cards. Figure 1 illustrates the control mechanisms of a Kanban-Like PCS under the two production authorization cards policies (D-KAP and S-KAP).
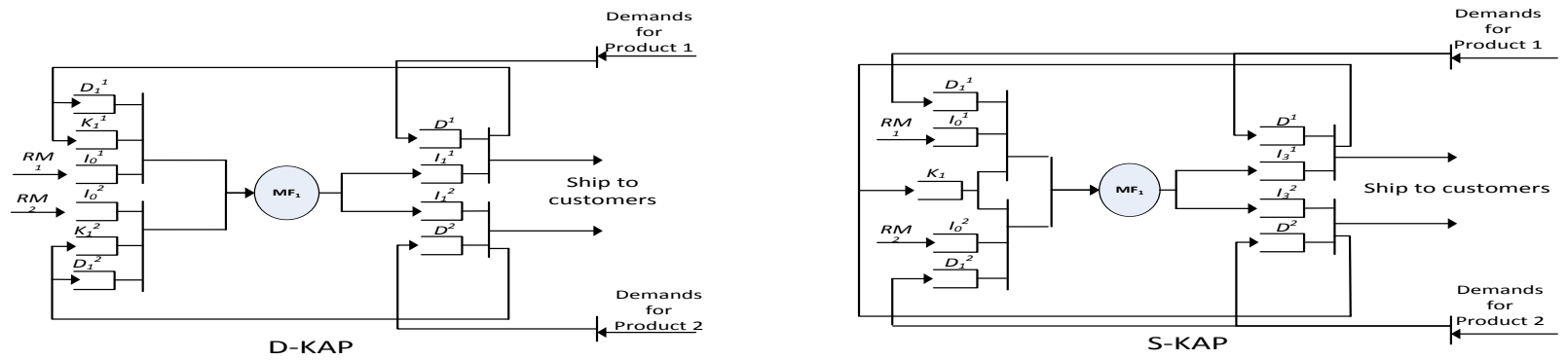

Figure 1: D-KAP and S-KAP in a multi-product stage.

Table 2: Description of symbols used in this paper.

\begin{tabular}{ll|ll}
\hline Symbol & \multicolumn{1}{c|}{ Description } & Symbol & Description \\
\hline$D_{1,2, \ldots}$ & Demand Card for stage $1,2, \ldots$ & $C C$ & CONWIP card in a S-KAP PCS \\
$D^{1,2, \ldots}$ & Demand for product $1,2, \ldots$ & $C C^{1,2, \ldots}$ & CONWIP card for product $1,2, \ldots$ in a D-KAP PCS \\
$D_{1,2, \ldots}^{1,2, \ldots}$ & Demand Card for product $1,2, \ldots$ at stage $1,2, \ldots$ & $M F_{1,2, \ldots}$ & Manufacturing Process unit at stage $1,2, \ldots$ \\
$K^{1,2, \ldots}$ & Kanban card for product $1,2, \ldots$ & $I_{1,2, \ldots}$ & Inventory output buffer for product $1,2, \ldots$ at stage $1,2, \ldots$ \\
$K_{1,2, \ldots}^{1,2, \ldots}$ & Kanban card for product $1,2, \ldots$ at stage $1,2, \ldots$ & $I_{0}^{1,2, \ldots}$ & Raw material Inventory output buffer for product $1,2, \ldots$ \\
& & & \\
\hline
\end{tabular}




\subsection{Kanban-Like Control Strategies under Investigation}

Generalized Kanban Control Strategy (GKCS), Extended Kanban Control Strategy (EKCS) and BKCONWIP are the three PCS investigated in this work. The findings of Baynat et al. (2002), showed that both GKCS and EKCS are capable of operating D-KAP and S-KAP. BK-CONWIP proposed by Onyeocha and Geraghty (2012), operates both D-KAP and S-KAP in a multi-product manufacturing environment.

The concept of GKCS focuses on harnessing and combining the benefits of KCS and BSCS to form one control strategy. GKCS uses two parameters in each stage in a production line to control inventory and authorize production. The two parameters found in use in GKCS are the base-stock of finished parts and the number of Kanbans. The basestock of the finished parts controls the total stage inventory while the number of Kanbans controls the quantity of products to be stored in a stage's output buffer (Dallery and Liberopoulos 2000, Karaesmen and Dallery 2000).

In a multi-product D-KAP GKCS, the Kanban is detached from a part when the part leaves the manufacturing process unit. The Kanban is sent upstream and made available for the authorization of a new similar part. A satisfied demand generates a demand card for the last stage in the line, if the demand card matches with a Kanban corresponding to the part-type in that stage, a demand card for that part-type is transmitted to the next stage upstream. If a Kanban for the part-type is not available at a stage, the upstream stage will not receive a demand card. The control mechanism of a multi-product multi-stage dedicated GKCS is shown in Figure 2.

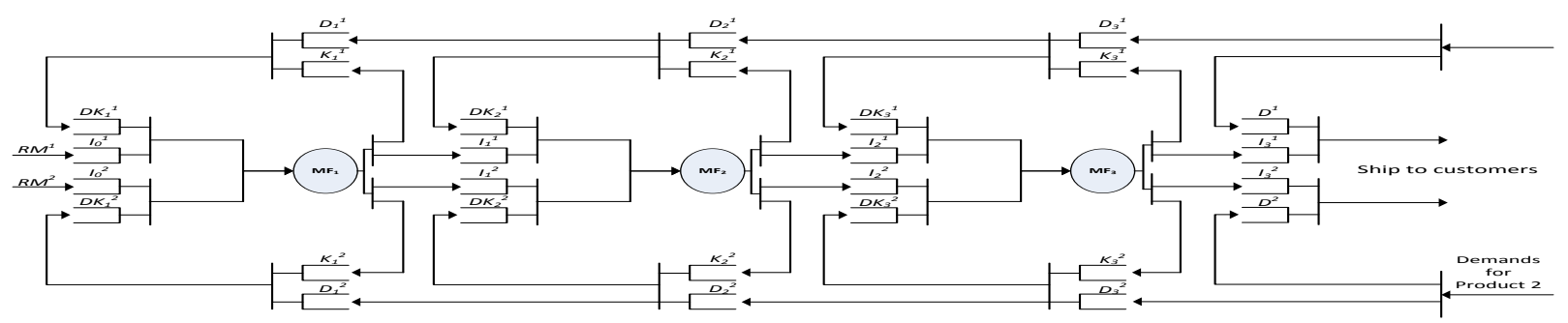

Figure 2: Control mechanism of a multi-product multi-stage D-KAP GKCS.

In the shared policy of a multi-product GKCS, the Kanbans are shared among all the part-types. The demand of each part-type is processed like the dedicated policy, except that the Kanban of each stage is shared, such that the different part-types can use any available Kanban for authorization for new part-type production. The shared Kanban is released from the finished part as it leaves the manufacturing process of that stage and returns to the Kanban resource pool of that stage. Just as with D-KAP GKCS, if there are no Kanbans available the upstream stage will not receive a demand card. The shared policy was found to perform better in controlling inventory, demand and processing time variations (Baynat et al. 2002). This is because of its ability to use any available Kanban to authorize part-type production rather than dedicating the Kanban to a specific part-type. Figure 3 gives an illustration of a control mechanism of a multiproduct multi-stage shared GKCS.

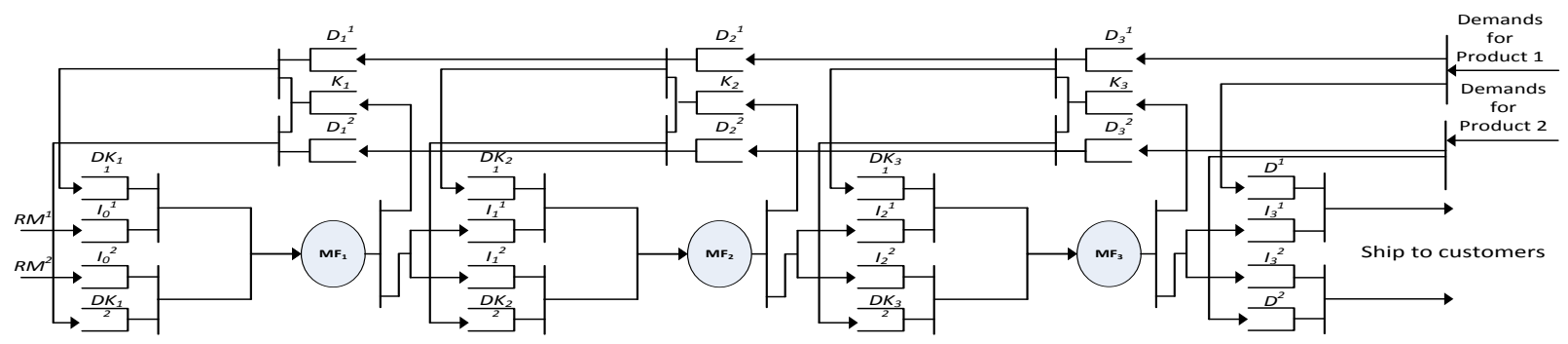

Figure 3: Control mechanism of a multi-product multi-stage S-KAP GKCS. 
EKCS like GKCS combines the merits of KCS and the merits of BSCS and also uses two parameters (basestock and number of Kanban) in its control mechanism. However the operations of EKCS systems are found to be simpler to that of GKCS (Dallery and Liberopoulos 2000). The primary difference between the EKCS and GKCS is that EKCS was developed to proffer a solution to variations in effective processing times or variations in demands. It controls the processing time variations and demand variations by using the same two parameters in each stage in a different way to GKCS. Demand information in EKCS is transmitted instantaneously and globally to all stages in a system. The authorization of part types in any stage requires the demand card to match with a Kanban in that stage. The Kanban attached to a part-type is detached from it as the part-type leaves the output buffer of that stage.

The major difference in the dedicated and shared policies of EKCS is the way the Kanban is allocated in the system. In D-KAP of EKCS, when a customer demands for a part-type, a corresponding Kanban type is used to authorize production of a part-type. If the demand for a part-type could not be matched with a Kanban associated to the part-type, the demand card would stay in the stage buffer as a backlog. While the shared policy of EKCS operates with the technique of allocating the Kanbans to any demand for any part type on the principle of first come first served. Figure 4 is an illustration of a control mechanism of D-KAP EKCS in multi-product multi-stage system while Figure 5 shows a control mechanism of S-KAP EKCS in multi-product multi-stage system.

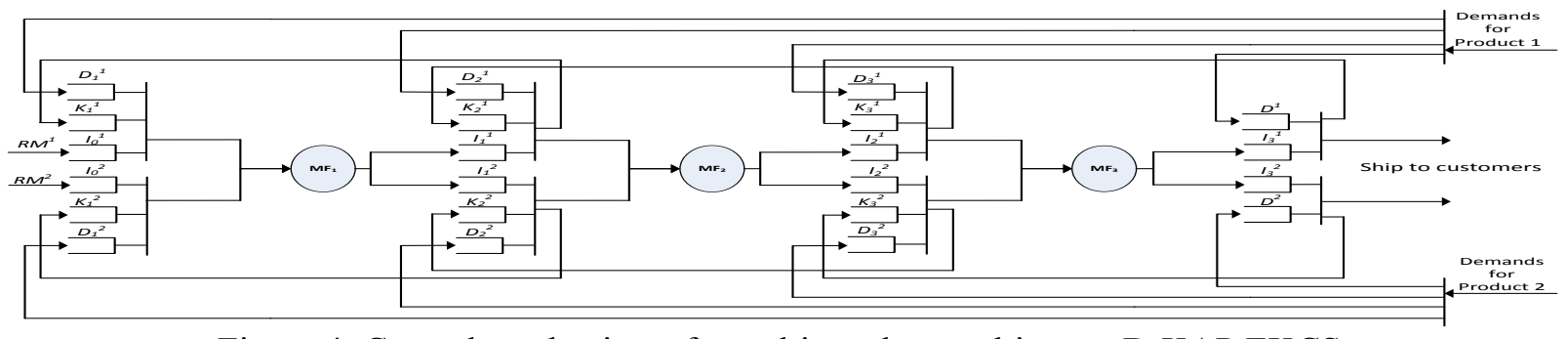

Figure 4: Control mechanism of a multi-product multi-stage D-KAP EKCS.

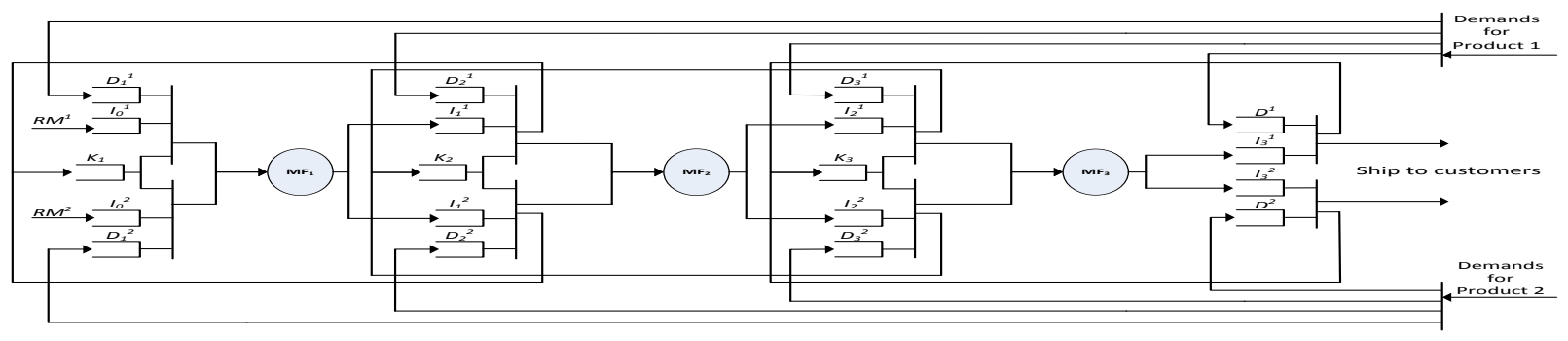

Figure 5: Control mechanism of a multi-product multi-stage S-KAP EKCS.

BK-CONWIP proposed by Onyeocha and Geraghty (2012), has three control parameters (Basestock, Kanban and CONWIP) such that each stage is controlled by two parameters while the entire system's WIP is controlled by one parameter. The main difference between the BK-CONWIP control mechanism and HK-CONWIP is that it uses a global transmission of the demand information which is initialized immediately when a demand occurs. CONWIP in BK-CONWIP controls the WIP of the entire system while Kanban controls the stage WIP. The last stage has no Kanbans. As in BSCS, a basestock in the final goods inventory is used to satisfy a demand for part-type and demand information is transmitted globally to all stages.

In the D-KAP mode of BK-CONWIP, a distinct quantity of CONWIP cards is dedicated to each parttype in a system for authorization of a corresponding or specific part-type. While in each stage, except for the last stage, Kanbans are dedicated to each part-type for stage authorization. On the other hand, in SKAP mode of BK-CONWIP, a specific quantity of CONWIP cards is planned and scheduled for the re- 
lease of all part-types into a system depending on the demand information and availability of CONWIP and stage Kanban cards (where applicable). CONWIP and Kanban cards are shared by all part-types in a system. Figures 6 and 7 illustrate the control mechanisms of multi-product of BK-CONWIP operating DKAP and S-KAP, respectively.

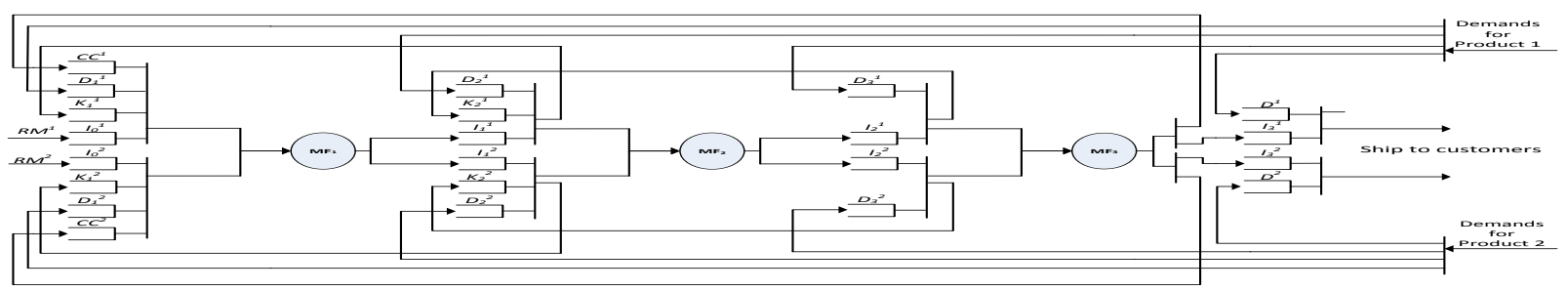

Figure 6: Control mechanism of multi-product D-KAP BK-CONWIP.

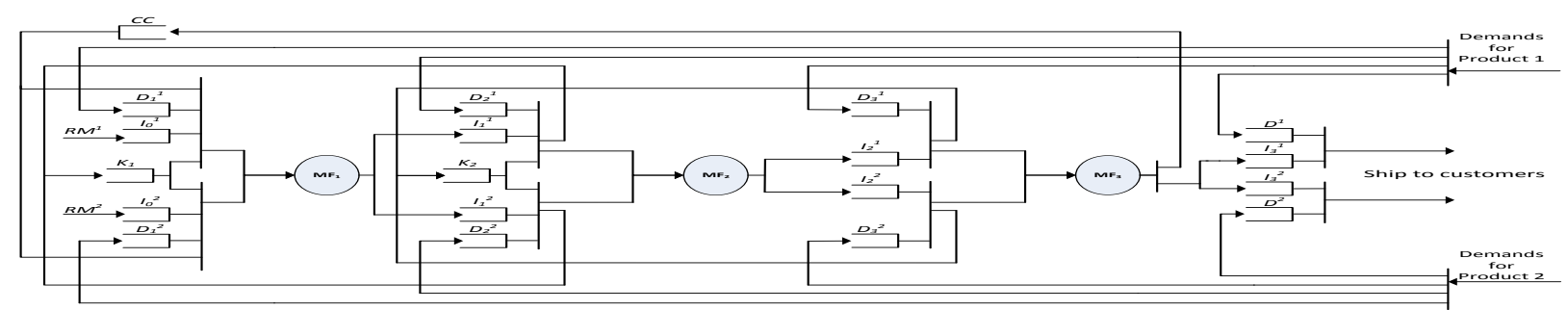

Figure 7: Control mechanism of multi-product S-KAP BK-CONWIP.

\section{SIMULATION MODEL AND EXPERIMENTAL DATA}

Simulation models were developed using ExtendSim simulation software for D-KAP and S-KAP GKCS as shown in Figures 2 and 3, D-KAP and S-KAP EKCS as shown in Figures 4 and 5 and S-KAP BKCONWIP as shown in Figure 7. The system modeled is an electronics multi-product manufacturing facility which produces four products in a serial five stage manufacturing line under an erratic demand profile. The system is highly automated and requires less input from operators during operations. The products are identical with the exception of color, a characteristic that does not influence processing times or result in set-ups at a production stage. Demands for product are made once a week in a lumpy irregular batch while the shipment or supply of finished goods is carried out in a two-hourly interval.

In modeling the system for the three Kanban-Like PCS, raw materials were considered as always available. Limitation on production of part-types depends on the availability of the authorization cards and/or the production capacity in cases where there is demand for part-type. The demand is generated in the model based on the empirical demand dataset provided by the company. The create block of the ExtendSim simulation software was used to generate and schedule demands on a weekly interval. The processing times are deterministic and all transfer times in the system are considered to be negligible. The five stages in the system are subject to random failure.. Finished goods are stored in a supermarket area in box quantities. Figure 8 provides a schematic representation of the four-product five-stage manufacturing system and the system configuration is presented in Table 3.

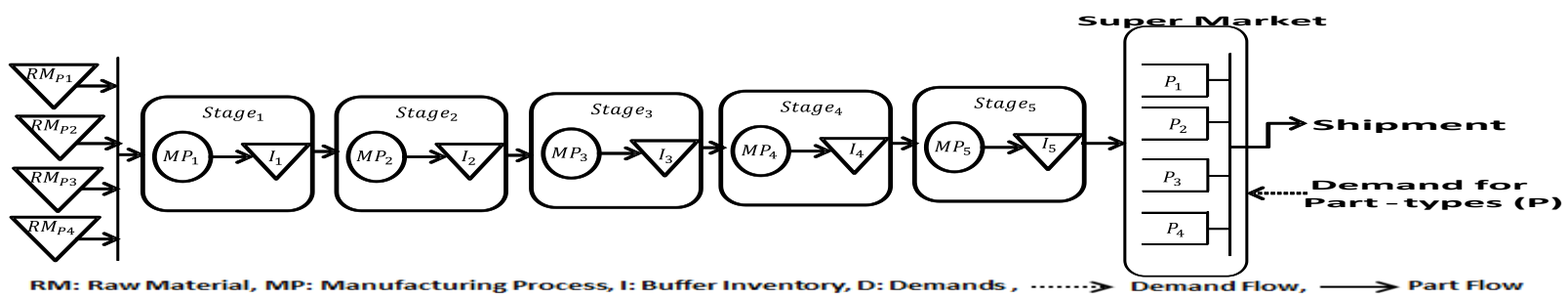

Figure 8: Schematic diagram of the system. 
Table 3: The configuration of the manufacturing system for modeling.

\begin{tabular}{|l|c|c|c|c|c|c|}
\hline & Product 1 & Product 2 & Product 3 & \multicolumn{2}{|c|}{ Product 4 } & \multicolumn{2}{|c|}{$\begin{array}{c}\text { Maintenance: Exponential Dis- } \\
\text { tribution Mean }\end{array}$} \\
\cline { 2 - 7 } Stage & $\begin{array}{c}\text { Lead } \\
\text { Times/Box } \\
\text { (Hours) }\end{array}$ & $\begin{array}{c}\text { Lead } \\
\text { Times/Box } \\
\text { (Hours) }\end{array}$ & $\begin{array}{c}\text { Lead } \\
\text { Times/Box } \\
\text { (Hours) }\end{array}$ & $\begin{array}{c}\text { Lead Times/Box } \\
\text { (Hours) }\end{array}$ & MTBF (Hours) & $\begin{array}{c}\text { MTTR } \\
\text { (Hours) }\end{array}$ \\
\hline 1 & 0.0975 & 0.0975 & 0.13 & 0.13 & 90 & 10 \\
\hline 2 & 0.0975 & 0.0975 & 0.13 & 0.13 & 90 & 10 \\
\hline 3 & 0.0975 & 0.0975 & 0.13 & 0.13 & 90 & 10 \\
\hline 4 & 0.0975 & 0.0975 & 0.13 & 0.13 & 90 & 10 \\
\hline 5 & 0.0975 & 0.0975 & 0.13 & 0.13 & 90 & 10 \\
\hline
\end{tabular}

The demand variation is random and unpredictable in nature. Each of the four products has a demand profile for a six week period. Table 4 shows the weekly demands for each product in box quantities $(90$ parts in a box for products 1 and 2 and 120 parts in a box for products 3 and 4). Data collected from the company shows the company's view of how demand was changing from four weeks (Week 20 as in the company's production Calendar) before production was due to commence (Week 24 as in the company's production Calendar) to one week after production began (Week 25 as in the company's production Calendar). The Week 20 demand profile is the view of demand that the company would have when placing orders to suppliers to ensure delivery on-time for production to commence in Week 24. Due to space limitations only the first and fifth data sets are presented in Table 4 . The weekly total demand profiles have approximately similar product volume except for the week 24 demand profile in which the demand for product 3 increased by approximately 800 boxes with no corresponding decrease in demand for other products. The product mix followed a similar trend except for week 25 that has a noticeable change in product mix. Table 5 provides a description of the total demand and the product mix. The system experiences backlog when demands are not met within a production week period. When demand is not fully satisfied, the total quantity (boxes) produced will be shipped out to customers while the unsatisfied demands are treated as a backlog and is added to the demand in the following week.

Table 4: Weekly demand profile.

\begin{tabular}{|c|c|c|c|c|c|c|}
\hline \multicolumn{7}{|c|}{ Week 20 Demand Profile } \\
\hline Product & Week 24 & Week 25 & Week 26 & Week 27 & Week 28 & Week 29 \\
\hline P1 & 130 & 184 & 131 & 159 & 125 & 147 \\
\hline $\mathrm{P} 2$ & 110 & 138 & 147 & 71 & 61 & 39 \\
\hline P3 & 542 & 452 & 404 & 503 & 247 & 483 \\
\hline P4 & 130 & 224 & 142 & 118 & 129 & 114 \\
\hline Total & 912 & 998 & 824 & 851 & 562 & 783 \\
\hline \multicolumn{7}{|c|}{ Week 25 Demand Profile } \\
\hline P1 & 103 & 25 & 111 & 122 & 119 & 97 \\
\hline P2 & 101 & 20 & 128 & 68 & 57 & 48 \\
\hline P3 & 481 & 544 & 461 & 412 & 461 & 429 \\
\hline P4 & 296 & 225 & 141 & 107 & 130 & 200 \\
\hline Total & 981 & 814 & 841 & 709 & 767 & 774 \\
\hline
\end{tabular}

Table 5: Changes in product mix and total demand volume across demand profiles.

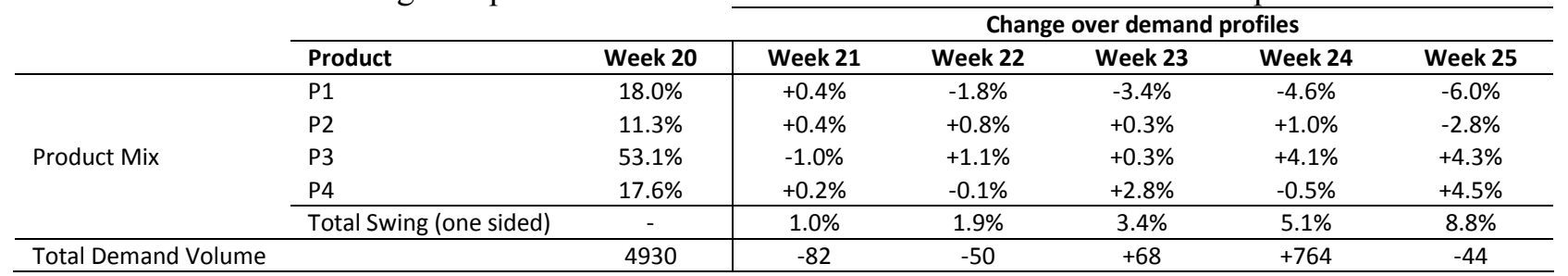


While for simulation and analysis purposes this system is treated as a terminating system, it was necessary to implement a warm-up period (allow a period of time to elapse over which no statistics are determined) to ensure the state of the system in the first week of interest would be similar to the real production line. To this end a four week warm-up period was chosen, by using the Welch graphical approach. The simulation experiments were carried out over thirty replications and ten weeks run length for each of the five models. The control parameters of the five models (D-KAP GKCS, S-KAP GKCS, D-KAP EKCS, S-KAP EKCS and S-KAP BK-CONWIP) for the week 20 view of the demand profiles were optimized using the Genetic Algorithm (GA) optimization block built into ExtendSim. An objective function was defined and encoded into the optimization block in order to achieve a targeted service level and backlog while minimizing inventory. GA applies the technique found in natural evolution to search for an optimal solution over a range of randomly generated population from the inputted data. The populated samples are screened and best fitted individuals are selected for further generation of offspring. The screening procedure is repeated until the best solution is found within a defined condition or terminates if a solution is not found within the specified conditions. For the purposes of the experiments reported here, the objective was to determine the parameters of a strategy such that it would achieve $100 \%$ service level with minimal WIP. Details of the search range and the optimal settings for each strategy and policy investigated are presented in Tables 6 and 7.

Table 6: Solution space and optimal settings for D-KAP of GKCS and EKCS.

\begin{tabular}{|c|c|c|c|c|c|c|c|c|c|}
\hline \multirow[b]{3}{*}{ Stage } & \multirow{3}{*}{$\begin{array}{c}\text { Parameter } \\
\text { Product }\end{array}$} & \multicolumn{8}{|c|}{ KAP-PCS } \\
\hline & & \multicolumn{4}{|c|}{ D-KAP GKCS } & \multicolumn{4}{|c|}{ D-KAP EKCS } \\
\hline & & $P 1$ & $P 2$ & $P 3$ & $P 4$ & $P 1$ & $P 2$ & P3 & $P 4$ \\
\hline 1 & Kanban & $1-3[2]$ & $1-3[2]$ & $1-5[4]$ & $1-4[3]$ & $19-30[23]$ & $10-15$ [11] & $20-35[30]$ & $11-17$ [16] \\
\hline 2 & Kanban & $1-4[2]$ & $1-4[3]$ & $6-12[11]$ & $2-5[4]$ & $11-24[15]$ & $7-12[8]$ & $25-50[45]$ & $15-30[21]$ \\
\hline 3 & Kanban & $2-6[5]$ & $1-4[3]$ & $9-16[15]$ & $6-10[9]$ & $15-30[29]$ & $15-30[17]$ & $25-50[50]$ & $20-40$ [33] \\
\hline 4 & Kanban & $15-25[18]$ & $5-9[8]$ & $19-30[29]$ & $15-25[17]$ & $20-40[38]$ & $20-40[27]$ & $30-60[54]$ & $20-40[26]$ \\
\hline & Kanban & $15-25[19]$ & $10-15[12]$ & $18-29[25]$ & $15-25[16]$ & $0-2[0]$ & $0-2[0]$ & $0-2[0]$ & $0-2[0]$ \\
\hline 5 & Basestock & $\begin{array}{l}200-400 \\
{[340] B}\end{array}$ & $\begin{array}{l}200-400 \\
{[240] B}\end{array}$ & $\begin{array}{c}1500-3500 \\
{[3000] B}\end{array}$ & $\begin{array}{l}200-400 \\
{[360] B}\end{array}$ & $\begin{array}{c}150-300 \\
{[240] B+K}\end{array}$ & $\begin{array}{c}100-200 \\
{[160] B+K}\end{array}$ & $\begin{array}{c}1500-2500 \\
{[2000]} \\
B+K\end{array}$ & $\begin{array}{c}200-400 \\
{[280] B+K}\end{array}$ \\
\hline
\end{tabular}

Table 7: Solution space and optimal settings for S-KAP of GKCS, EKCS and BK-CONWIP.

\begin{tabular}{|c|c|c|c|c|c|c|c|c|c|c|c|c|c|}
\hline & & \multicolumn{12}{|c|}{ KAP-PCS } \\
\hline Stage & Parameter & \multicolumn{4}{|c|}{ S-KAP GKCS } & \multicolumn{4}{|c|}{ S-KAP EKCS } & \multicolumn{4}{|c|}{ S-KAP BK-CONWIP } \\
\hline 1 & Kanban & \multicolumn{4}{|c|}{$5-15[10] K$} & \multicolumn{4}{|c|}{$250-300[290] K$} & \multicolumn{4}{|c|}{$250-300[289] K$} \\
\hline 2 & Kanban & \multicolumn{4}{|c|}{$5-15[11] K$} & \multicolumn{4}{|c|}{$100-200[150] K$} & \multicolumn{4}{|c|}{$100-200[150] K$} \\
\hline 3 & Kanban & \multicolumn{4}{|c|}{$12-19[17] K$} & \multicolumn{4}{|c|}{$150-300[200] K$} & \multicolumn{4}{|c|}{$150-300[200] K$} \\
\hline 4 & Kanban & \multicolumn{4}{|c|}{$18-25[20] \mathrm{K}$} & \multicolumn{4}{|c|}{$250-350[300] K$} & \multicolumn{4}{|c|}{$150-300[250] K$} \\
\hline \multirow[b]{3}{*}{5} & Kanban & \multicolumn{4}{|c|}{$31-50[40] K$} & \multicolumn{4}{|c|}{$0-5[0] K$} & \multicolumn{4}{|c|}{ Not Applicable } \\
\hline & Product & $P 1$ & $P 2$ & $P 3$ & $P 4$ & $P 1$ & $P 2$ & $P 3$ & $P 4$ & $P 1$ & $P 2$ & $P 3$ & $P 4$ \\
\hline & Basestock & $\begin{array}{c}200- \\
400 \\
{[340]} \\
B\end{array}$ & $\begin{array}{c}200- \\
300 \\
{[239]} \\
B\end{array}$ & $\begin{array}{c}2000- \\
3050 \\
{[3000]} \\
B\end{array}$ & $\begin{array}{c}200- \\
400 \\
{[360]} \\
B\end{array}$ & $\begin{array}{c}280- \\
400 \\
{[340]} \\
B+K\end{array}$ & $\begin{array}{c}200- \\
300 \\
{[280]} \\
B+K \\
\end{array}$ & $\begin{array}{c}1500- \\
2500 \\
{[2000]} \\
B+K\end{array}$ & $\begin{array}{c}200- \\
400 \\
{[340]} \\
B+K \\
\end{array}$ & $\begin{array}{c}150- \\
250 \\
{[210]} \\
B\end{array}$ & $\begin{array}{c}100- \\
200 \\
{[140]} \\
B\end{array}$ & $\begin{array}{c}1500- \\
2500 \\
{[1900]} \\
B\end{array}$ & $\begin{array}{c}150- \\
300 \\
{[270]} \\
B\end{array}$ \\
\hline System & CONWIP & \multicolumn{4}{|c|}{ Not Applicable } & \multicolumn{4}{|c|}{ Not Applicable } & \multicolumn{4}{|c|}{$\begin{array}{l}250-350 \\
{[300] K}\end{array}$} \\
\hline
\end{tabular}

$K-$ Kanban only, B+K-Basestock+Kanban, P-Product, B-Basestock only, [O.S]-Optimal values for the control parameters.

\section{EXPERIMENTAL RESULTS}

The behavior of the strategies and policies were observed, under changing demand profiles. The system parameters and the optimized settings from the week 20 view were maintained while changing the demand profiles in order to investigate the performance of the strategies and policies to demand changes. The average Total Service Level (TSL) and the average Total WIP (TWIP) of each PCS and/or policy are presented in Figure 9, while the average Total Service Level (TSL) and the cumulative Total Backlog 
(TBL) of each PCS and/or policy are shown in Figure 10. The results showed the WIP level of each PCS and the policies used in achieving targeted service level of $100 \%$ for week 20 profile and subsequently the performance of the PCS and polices as the demand profile changes.

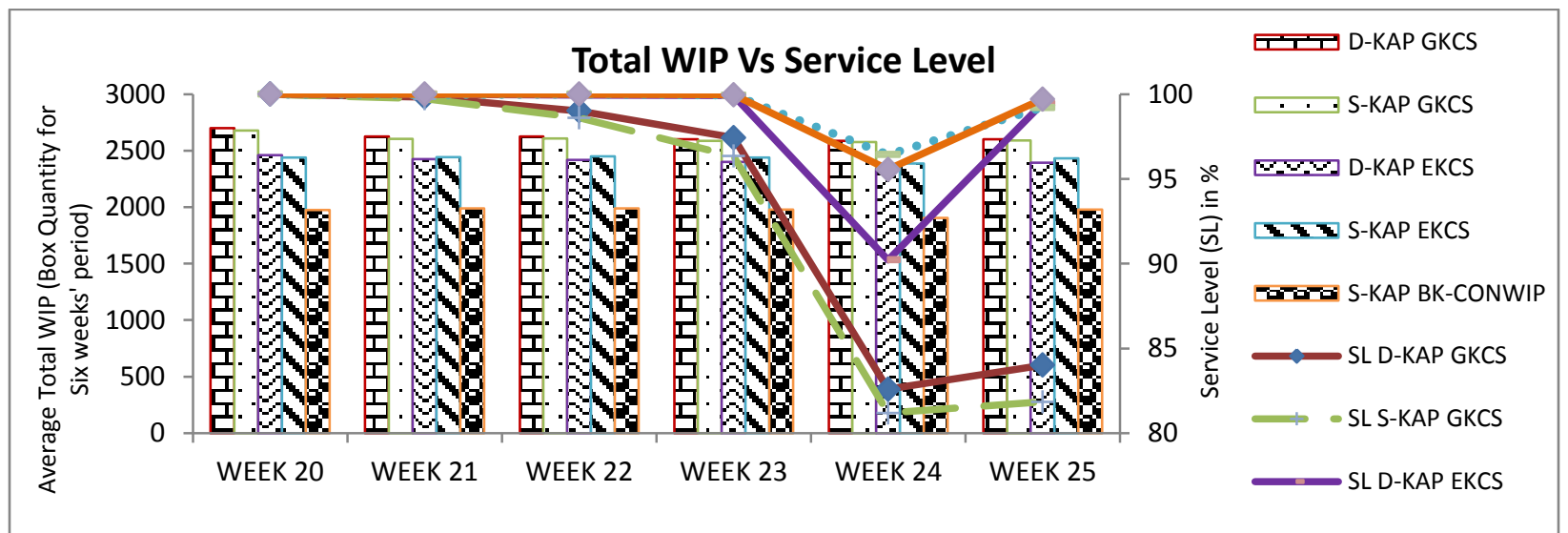

Figure 9: The results of average TSL and average TWIP over six weeks period.

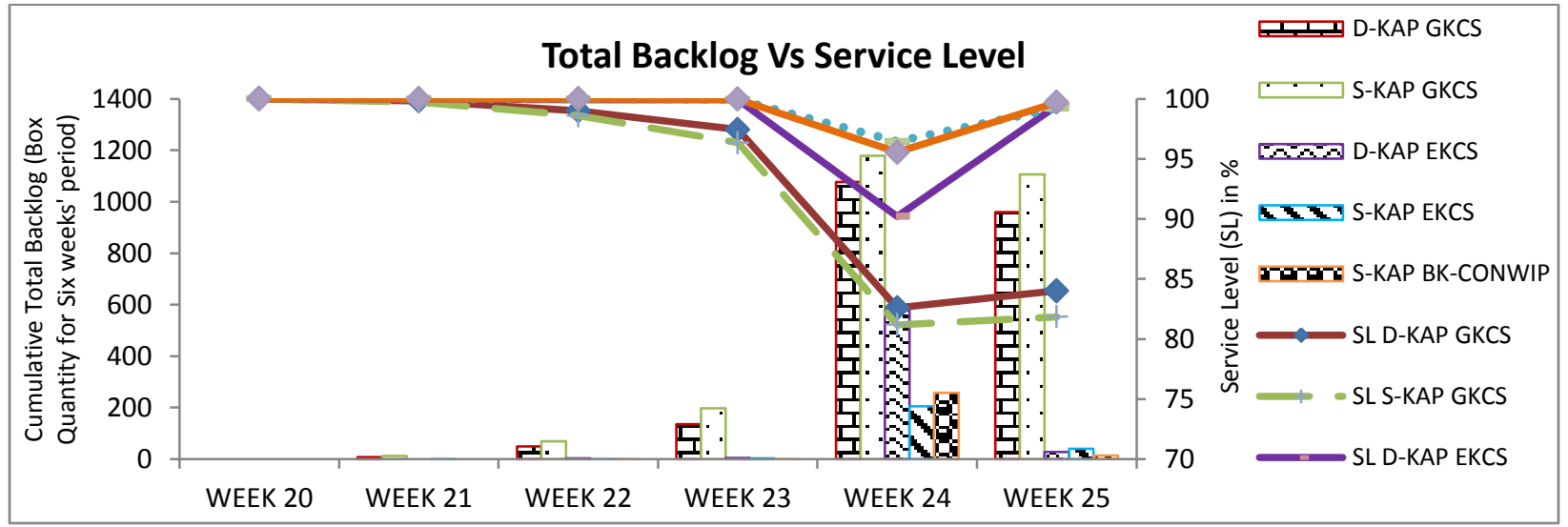

Figure 10: The results of average TSL and cumulative TBL over six weeks period.

The procedure for screening and selection of the best system proposed by Nelson et al. (2001), was used to analysis the output of the simulation models (TWIP and TSL). The procedure uses Rinott's twostage sampling technique in determining a superior system, while rejecting inferior systems during the process without additional simulation (cf. Nelson et al. 2001). Table 8 provides results of the Rinott's two-stage sampling technique for TWIP of week 20 view while, a summary of all the weeks profiles for TWIP and TSL is provided in Table 9. Rinott's two sampling procedure control parameters used in this work are as follows: $k=5$, where $k$ is the number of alternative systems for comparison. $n_{0}=30, n_{0}$ is the initial number of replications for each strategy. $N_{i}$ is the number of supplementary simulation required for further screening. $S_{i}^{2}$ is the variance of the sample data (TWIP or TSL), $\bar{Y}_{i}$ is the average of the sample data, $W_{i j}=t\left(\frac{s_{i}^{2}}{n_{o}}+\frac{s_{j}^{2}}{n_{o}}\right)^{0.5}, \alpha=0.1, \alpha$ is the overall confidence level of $90 \%$ for the combined procedure and $95 \%$ confidence level for each of the procedures, such that $\alpha_{0}=\alpha_{1}=\frac{\alpha}{2}=0.05$. A significant difference, $\varepsilon$, of 30 boxes and $0.2 \%$ service level was specified by the company for the purposes of comparing the systems on the basis of TWIP and TSL, respectively. Rinott's integral $h$ is given as $h=h(1-$ $\left.\alpha_{1}, n_{0}, k\right)=3.303$, and $t$ is given as $t=t_{1-\left(1-\alpha_{0}\right)^{\frac{1}{k-1}, n_{0}-1}}=2.655$ 
Onyeocha, Khoury, and Geraghty

Table 8: Results from screening stage of Nelson's procedure for total WIP in the week 20 demand profile.

\begin{tabular}{|c|c|c|c|c|c|c|c|c|}
\hline PCS & $i$ & $n_{0}$ & $\bar{Y}_{i}$ & $S_{i}^{2}$ & $j$ & $W_{i j}$ & $\bar{Y}_{i}+\max \left(0, W_{i j}-\varepsilon\right)$ & Keep? \\
\hline \multirow{4}{*}{ D-KAP GKCS } & \multirow{4}{*}{1} & \multirow{4}{*}{30} & \multirow{4}{*}{2699.52} & \multirow{4}{*}{1518.35} & 2 & 2.470 & 2680.90 & \multirow{4}{*}{ eliminate } \\
\hline & & & & & 3 & 13.121 & 2460.29 & \\
\hline & & & & & 4 & 21.652 & 2440.21 & \\
\hline & & & & & 5 & 14.338 & 1977.47 & \\
\hline \multirow{4}{*}{ S-KAP GKCS } & \multirow{4}{*}{2} & \multirow{4}{*}{30} & \multirow{4}{*}{2680.90} & \multirow{4}{*}{1718.10} & 1 & 2.470 & 2699.52 & \multirow{4}{*}{ eliminate } \\
\hline & & & & & 3 & 14.452 & 2460.29 & \\
\hline & & & & & 4 & 22.964 & 2440.21 & \\
\hline & & & & & 5 & 13.835 & 1977.47 & \\
\hline \multirow{4}{*}{ D-KAP EKCS } & \multirow{4}{*}{3} & \multirow{4}{*}{30} & \multirow{4}{*}{2460.29} & \multirow{4}{*}{798.96} & 1 & 13.121 & 2699.52 & \multirow{4}{*}{ eliminate } \\
\hline & & & & & 2 & 14.452 & 2680.90 & \\
\hline & & & & & 4 & 17.644 & 2440.21 & \\
\hline & & & & & 5 & 13.807 & 1977.47 & \\
\hline \multirow{4}{*}{ S-KAP EKCS } & \multirow{4}{*}{4} & \multirow{4}{*}{30} & \multirow{4}{*}{2440.21} & \multirow{4}{*}{1385.38} & 1 & 21.652 & 2699.52 & \multirow{4}{*}{ eliminate } \\
\hline & & & & & 2 & 22.964 & 2680.90 & \\
\hline & & & & & 3 & 17.644 & 2460.29 & \\
\hline & & & & & 5 & 24.109 & 1977.47 & \\
\hline \multirow{4}{*}{ S-KAP BK-CONWIP } & \multirow{4}{*}{5} & \multirow{4}{*}{30} & \multirow{4}{*}{1977.47} & \multirow{4}{*}{2021.28} & 1 & 14.338 & 2699.52 & \multirow{4}{*}{ keep } \\
\hline & & & & & 2 & 13.835 & 2680.90 & \\
\hline & & & & & 3 & 13.807 & 2460.29 & \\
\hline & & & & & 4 & 24.109 & 2440.21 & \\
\hline
\end{tabular}

Table 9: Summary of results from Nelson's procedure applied to all demand profiles.

\begin{tabular}{ll|llllll}
\hline PCS & Metric & Week 20 & Week 21 & Week 22 & Week 23 & Week 24 & Week 25 \\
\hline \multirow{2}{*}{ D-KAP GKCS } & TWIP & Eliminate & Eliminate & Eliminate & Eliminate & Eliminate & Eliminate \\
& Service Level & Keep & Eliminate & Eliminate & Eliminate & Eliminate & Eliminate \\
\hline \multirow{2}{*}{ S-KAP GKCS } & TWIP & Eliminate & Eliminate & Eliminate & Eliminate & Eliminate & Eliminate \\
& Service Level & Keep & Eliminate & Eliminate & Eliminate & Eliminate & Eliminate \\
\hline \multirow{2}{*}{ D-KAP EKCS } & TWIP & Eliminate & Eliminate & Eliminate & Eliminate & Eliminate & Eliminate \\
& Service Level & Keep & Keep & Eliminate & Eliminate & Eliminate & Eliminate \\
\hline \multirow{2}{*}{ S-KAP EKCS } & TWIP & Eliminate & Eliminate & Eliminate & Eliminate & Eliminate & Eliminate \\
& Service Level & Keep & Eliminate & Eliminate & Eliminate & Keep & Eliminate \\
\hline \multirow{2}{*}{ S-KAP BK-CONWIP } & TWIP & Keep & Keep & Keep & Keep & Keep & Keep \\
& Service Level & Keep & Keep & Keep & Keep & Keep & Keep \\
\hline
\end{tabular}

\section{DISCUSSION AND CONCLUSION}

The results of using Nelson's screening and selection procedure show that for three of the demand profiles examined (Week 22, 23 and 25) S-KAP BK-CONWIP is the only survivor from the screening procedure for both performance metrics; Total Service Level and Total WIP. For the Week 20, 21 and 24 demand profiles S-KAP BK-CONWIP is the only KAP-PCS to survive both screening procedures simultaneously. In the Week 20 demand profile all systems survived the screening procedure for TSL, which is not surprising as the optimization was conducted on this demand profile to achieve $100 \%$ Service Level. S-KAP BK-CONWIP was the only system to survive the screening procedure for Total WIP in this demand profile. In the Week 21 demand profile D-KAP EKCS and S-KAP BK-CONWIP survived the screening procedure for TSL (both systems delivered 100\% Service Level). However, S-KAP BKCONWIP was the only system to survive the Total WIP screening procedure. In the Week 24 demand profile, which represents a spike in demand volume and moderate shift in product mix, S-KAP EKCS and S-KAP BK-CONWIP were both survivors for TSL. However, S-KAP BK-CONWIP was the only survivor for Total WIP in this demand profile. Interestingly, from a visual inspection of Figures 9 and 10 an observer would have selected S-KAP EKCS as the preferred system for both performance metrics for this demand profile. However, S-KAP BK-CONWIP exhibited less variability in over the 30 replications in the Total WIP performance metric than S-KAP EKCS owing to the use of CONWIP cards. 
In general, it was observed that S-KAP performed better than D-KAP in terms of the performance metrics. S-KAP used a lower number of authorization cards in its control mechanism and recorded lower WIP and lower backlogs compared to D-KAP. In terms of service level achieved (TSL), S-KAP EKCS was similar to or outperformed D-KAP EKCS especially when the surge in demand volume occurred in the Week 24 demand profile. However, the opposite was observed for GKCS where D-KAP outperformed S-KAP in terms of TSL. This is attributable to a higher basestock levels and as a result higher WIP being maintained by the D-KAP version of GKCS. It is interesting to note that the demand profiles from Week 20 to 23, inclusively, demonstrate small variation in product mix and demand volume but the performance of GKCS, irrespective of KAP used, degrades from the Week 21 demand profile for all performance metrics. Also GKCS was the worst performer for the Week 24 and Week 25 demand profiles, irrespective of KAP employed. The Week 24 demand profile represents a sudden spike in demand volume ( +764 boxes) with a moderate shift in product mix $(\mathrm{P} 1-4.6 \%, \mathrm{P} 2+1.0 \%, \mathrm{P} 3+4.1 \%$ and $\mathrm{P} 4-0.5 \%-$ total swing 5.1\%). The Week 25 demand profile presents similar total demand volume to the Week 20 demand profile ( -44 boxes) with significant swings in product mix across all products (P1 -6.0\%, P2 -2.8\%, P3 $+4.3 \%$ and $\mathrm{P} 4+4.5 \%$ - total swing $8.8 \%$ ). This indicates that GKCS is very sensitive to the optimization conditions, i.e., deterministic demand profile. It would be interesting to evaluate if GKCS would exhibit similar performance degradation if the parameters of GKCS were optimized for a stochastic demand profile.

In conclusion, we have demonstrated that it is feasible to design and implement a Kanban-Like PCS that is capable of quick response to demand variations in a multi-product system. Overall, S-KAP BK-CONWIP provides the best flexibility in terms of maximizing service level and minimizing WIP in the presence of unstable demands resulting from increased total demand volume and/or unanticipated changes in product mix. While the performances of all systems degraded significantly when a surge in demand volume occurred, S-KAP versions of EKCS and BK-CONWIP maintained good service levels, above $95 \%$. When presented with a demand profile that modeled significant swings in product mix with no significant changes to total demand volume, S-KAP versions of EKCS and BK-CONWIP as well as D-KAP EKCS maintained very high service levels (above 99\%). The 'good' performance of D-KAP EKCS in terms of service level is a result of maintaining significantly higher WIP than the other systems and, as the company sponsor emphasizes $100 \%$ SL with minimal WIP, this system would be the least preferred of the three. Further study on the robustness of these KAP-PCS systems would provide clearer understanding of suitability of these systems for multi-product environments with unstable demand.

\section{REFERENCES}

Akturk, M. S., and F. Erhun. 1999. "An Overview of Design and Operational Issues of Kanban Systems." International Journal of Production Research 37:3859-3881.

Bard, J. F., and B. Golany. 1991. "Determining the Number of Kanbans in a Multi-product, Multi-stage Production System.” International Journal of Production Research 29:881-895.

Baynat, B., J. A. Buzacott, and Y. Dallery. 2002. "Multi-product Kanban-like Control Systems." International Journal of Production Research 40:4225-4255.

Bonvik, A. M., and S. B. Gershwin. 1996. "Beyond Kanban: Creating and Analysing Lean Shop Floor Control Policies." Manufacturing and Service Operations Management: MSOM Proceedings, 4651. Hanover, USA.

Dallery, Y., and G. Liberopoulos. 2000. "Extended Kanban Control System: Combining Kanban and Base Stock." IIE Transactions 32:369-386.

Deleersnyder, J. L., T. J. Hodgson, R. E. King, P. J. O’Grady, and A. Savva. 1992. “Integrating Kanban Type Pull Systems and MRP Type Push Systems: Insights from a Markovian Model." IIE Transactions 24:43-56. 
Duenyas, I. 1994. "A Simple Release Policy for Networks of Queues with Controllable Inputs." Operations Research 42:1162-1171.

Hum, S. H., and C. K. Lee. 1998. "JIT Scheduling Rules: A Simulation Evaluation.” Omega 26:381-395.

Karaesmen, F., and Y. Dallery. 2000. "A Performance Comparison of Pull Type Control Mechanisms for Multi-Stage Manufacturing.” International Journal of Production Economics 68:59-71.

Krejewski, L. J., B. E. King, L. P. Ritzman, and D. S. Wong. 1987. "Kanban, MRP, and Shaping the Manufacturing Environment." Management Science 33:39-57.

Lee, L. C. 1989. "A Comparative Study of the Push and Pull Productions Systems." International Journal of Operations \& Production Management 9:5-18.

Nelson, B. L., J. Swann, D. Goldsman, and W. Song. 2001. "Simple Procedures for Selecting the Best Simulated System when the number of Alternatives is Large." Operations Research 49:950-963.

Onyeocha, C. E., and J. Geraghty. 2012. "A Modification of the Hybrid Kanban-CONWIP Production Control Strategy for Multi-product Manufacturing Systems." International Manufacturing Conference (IMC29) proceedings, University of Ulster, Belfast, UK.

Ryan, S. M., and J. Vorasayan. 2005. "Allocating Work in Process in Multi-product CONWIP System with Lost Sales." International Journal of Production Research 43:223-246.

Ryan, S. M., B. Baynat, and F. Choobineh. 2000. "Determining Inventory Levels in a CONWIP Controlled Job Shop." IIE Transactions 32:105-114.

Satyam, K., and A. Krishnamurthy. 2008. Performance Evaluation of a Multi-product System under CONWIP Control.” IIE Transactions 40:252 - 264.

Spearman, M. L., D. Woodruff, and W. Hopp. 1990. "CONWIP: A P ull Alternative to Kanban." International Journal of Production Research 28:879-894.

\section{AUTHOR BIOGRAPHIES}

CHUKWUNONYELUM EMMANUEL ONYEOCHA is a PhD candidate in the School of Mechanical and Manufacturing Engineering at Dublin City University, Ireland. His research interest is in lean manufacturing, design of production control strategies, modeling and simulation optimization of manufacturing systems and supply-chain management. His email address is chukwunonyelum.onyeocha2@mail.dcu.ie.

JOSEPH KHOURY is Vice President, General Manager - European Automotive of Methode Electronics Inc., His research interest is in design of efficient production control strategies in complex manufacturing systems and supply-chain management. His email is joseph.khoury@methodegermany.com.

JOHN GERAGHTY is a lecturer in the School of Mechanical and Manufacturing Engineering at Dublin City University, Ireland. His research interest is in modeling and optimization of manufacturing systems and supply-chain management. His email address is john.geraghty@dcu.ie and his website address is http://www.dcu.ie/info/staff_member.php?id_no=714. 